Check for updates

Cite this: Chem. Commun., 2020, 56,12821

Received 16th August 2020,

Accepted 17th September 2020

DOI: $10.1039 / \mathrm{d} 0 \mathrm{cc} 05578 f$

rsc.li/chemcomm

\section{Reversible switching from a three- to a nine-fold degenerate dynamic slider-on-deck through catenation $\dagger$}

\author{
Vishnu Verman Rajasekaran, (D) Indrajit Paul (D) and Michael Schmittel (D)*
}

Two dynamic slider-on-deck assemblies, i.e. a two-component threefold degenerate $\left(k_{298}=34.9 \mathrm{kHz}\right)$ and a catenated threecomponent ninefold degenerate $\left(k_{298}=27.9 \mathrm{kHz}\right)$ system, were quantitatively interconverted. Inspection of their computed structures revealed an allosteric effect on the sliding rates due to the spatial interaction between the components.

Since the first breathtaking demonstration of their preparation by simple self-assembly, catenanes ${ }^{1}$ have assumed an outstanding importance in the arena of synthetic molecular machines. ${ }^{2-4}$ These mechanically interlocked molecules have been the basis for constructing motors, ${ }^{5}$ switches, ${ }^{6}$ solid-state electronics, ${ }^{7}$ and DNA-based architectures ${ }^{8}$ mainly capitalizing on the relative translational and/or rotational dynamics between the rings. The inherent dynamics has been studied in much detail, as reported initially in Sauvage's ground-breaking [2]catenane paper, ${ }^{9}$ followed by many studies on electrochemically, ${ }^{10}$ light- ${ }^{11}$ and chemically ${ }^{12}$ induced motion. ${ }^{13}$

To date, a lot of impressive examples of coordination-driven multicomponent dynamic catenanes have been reported, ${ }^{14}$ but dynamics has been usually limited to the relative motion between rings. ${ }^{15}$ In contrast, the concept of a multicomponent dynamic catenate exhibiting nanomechanical motion other than dynamics between rings has been a relatively unexplored facet. ${ }^{16}$ Moreover, to the best of our knowledge, the allosteric adjustment of nanomechanical motion in multicomponent ${ }^{17}$ dynamic catenanes adds new prospects for the field of catenatebased machines.

In this report, we elaborate on aspects of dual dynamics in catenate DS2, with the interconversion between topological structures (catenate $\rightarrow 2 \times$ macrocycles) being only one facet (Scheme 1). A similar system developed by Sauvage and Heitz

Center of Micro and Nanochemistry and Engineering, Organische Chemie I,

Universität Siegen, Adolf-Reichwein-Str. 2, D-57068, Germany.

E-mail: schmittel@chemie.uni-siegen.de; Tel: +49(0) 2717404356

$\dagger$ Electronic supplementary information (ESI) available. See DOI: 10.1039/ docc05578f on the basis of homoleptic $\left[\mathrm{Cu}(\text { phen })_{2}\right]^{+}$and $N_{\text {py }} \rightarrow$ ZnPor (zinc porphyrin) interactions, has emphasized the effect of geometric parameters (distance and angles) in coordination-based catenate assemblies. ${ }^{18}$ The second facet of dynamics encompasses the feature that each macrocyclic unit of catenate DS2 and of DS1 is a highly dynamic slider-on-deck system in itself (e.g. DS1, Scheme 1). In more detail, the dynamic two-component slider-on-deck DS1 constitutes a macrocyclic system with three degenerate states that reversibly and quantitatively converts into the three-component dynamic slider-on-deck catenate DS2 with $3 \times 3$ degenerate states. Interconversion is accomplished by addition/removal of $\mathrm{Cu}^{+}$ions. Moreover, the intrasupramolecular dynamics, the rate-determining step of which requires $N_{\text {py }} \rightarrow$ ZnPor bond cleavage, is affected by an allosteric effect originating at the remote metal-phenanthroline coordination site.

Synthesis and characterization of biped $\mathbf{1}$ and deck 2 are described in the ESI. $\dagger$ At first, we decided to separately prepare the multicomponent dynamic slider-on-deck systems DS1 and DS2 capitalizing on homoleptic $\left[\mathrm{Cu}\left(\text { phen } \mathrm{Ar}_{2}\right)_{2}\right]^{+}$complexation and/or $N_{\text {py }} \rightarrow$ ZnPor interactions, i.e. two binding motifs that are known to be orthogonal. ${ }^{19}$ Biped 1 and deck 2 were mixed

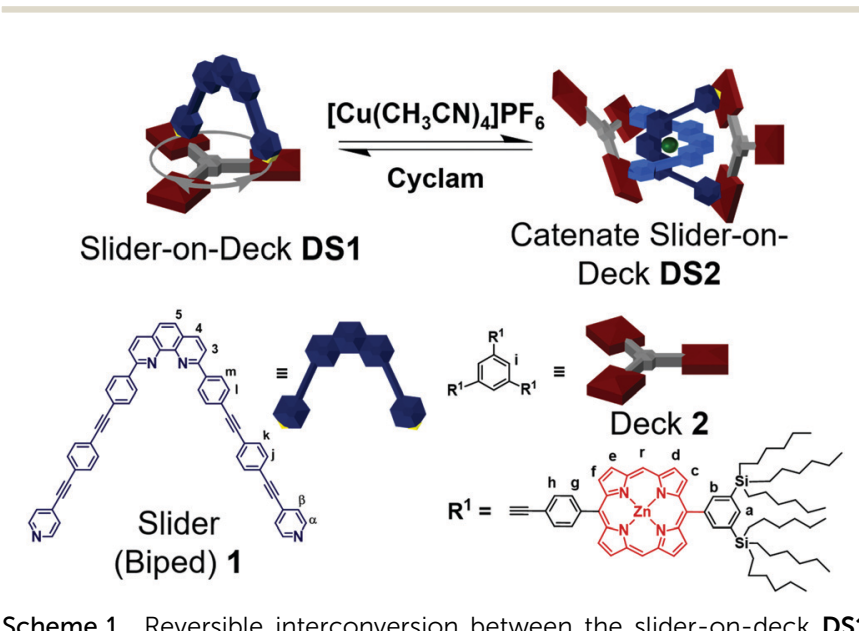

Scheme 1 Reversible interconversion between the slider-on-deck DS1 and the dynamic catenate slider DS2. Sliding motion shown for DS1. 


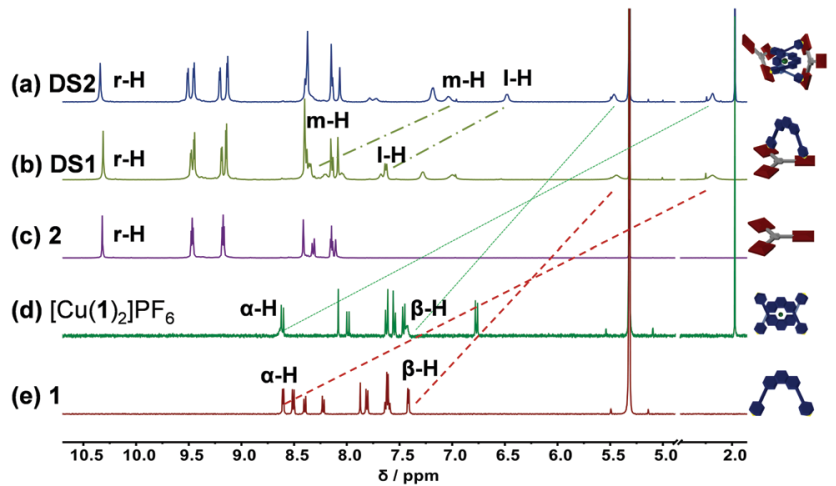

Fig. 1 Comparison of partial ${ }^{1} \mathrm{H}-\mathrm{NMR}\left(500 \mathrm{MHz}, \mathrm{CD}_{2} \mathrm{Cl}_{2}, 298 \mathrm{~K}\right)$ of (a) catenate slider-on-deck DS2 $=\left[\mathrm{Cu}(\mathbf{1})_{2} \cdot(\mathbf{2})_{2}\right] \mathrm{PF}_{6} ;(\mathrm{b})$ slider-on-deck DS1 = [1.2]; (c) free deck 2; (d) $\left[\mathrm{Cu}(\mathbf{1})_{2}\right] \mathrm{PF}_{6}$; (e) slider $\mathbf{1}$.

in a $1: 1$ ratio quantitatively furnishing DS1 (Fig. 1b). Complex DS1 was fully characterized by ${ }^{1} \mathrm{H},{ }^{1} \mathrm{H}^{-1} \mathrm{H}$ COSY, ${ }^{1} \mathrm{H}^{-1} \mathrm{H}$ NOESY, ${ }^{1} \mathrm{H}$ DOSY NMR studies and elemental analysis (ESI, $\dagger$ Fig. S17S19, S25). The slider assembly was identified by the changes in the ${ }^{1} \mathrm{H}$-NMR signals of protons $\alpha-\mathrm{H}, \beta-\mathrm{H}$ of the biped 1 and $\mathrm{r}-\mathrm{H}$ of the deck 2 (Fig. 1b, c and e). There are stark changes in the signals of protons $\alpha-\mathrm{H}$ and $\beta-\mathrm{H}$ of $\mathbf{1}$ as they experience the porphyrin's shielding ring current upon axial $N_{\mathrm{py}} \rightarrow$ ZnPor coordination thus shifting the r-H signals of 2 slightly upfield.

Similarly, 1, 2 and $\mathrm{Cu}^{+}$were mixed in a $2: 2: 1$ ratio to quantitatively assemble DS2. The complex DS2 was fully characterized by ${ }^{1} \mathrm{H}$ NMR, ${ }^{1} \mathrm{H}^{-1} \mathrm{H}$ COSY, ${ }^{1} \mathrm{H}^{-1} \mathrm{H}$ NOESY NMR, ${ }^{1} \mathrm{H}$ DOSY (ESI, $\dagger$ Fig. S20-S22, S24), and elemental analysis. Formation of the dynamic catenate DS2 was ascertained by changes in the ${ }^{1} \mathrm{H}-\mathrm{NMR}$ signature of protons $\mathrm{m}-\mathrm{H}, \mathrm{l}-\mathrm{H}, \alpha-\mathrm{H}, \beta-\mathrm{H}$ of $\mathbf{1}$ and $\mathrm{r}-\mathrm{H}$ of 2. Signals of protons $\alpha-\mathrm{H}$ and $\beta-\mathrm{H}$ significantly shifted upfield, while those of $\mathrm{m}-\mathrm{H}$ and $\mathrm{l}-\mathrm{H}$ from the $\left[\mathrm{Cu}(\mathbf{1})_{2}\right]^{+}$unit broadened and shifted slightly upfield upon catenation and axial coordination with 2 (Fig. 1a and d). The broadening is a strong indication of dynamic exchange rates faster than the NMR timescale.

Finally, we were interested in reversibly interconverting the two slider-on-deck systems and thus first assembled DS1 in solution as described above. Follow-up addition of 0.5 equiv. of $\left[\mathrm{Cu}\left(\mathrm{CH}_{3} \mathrm{CN}\right)_{4}\right] \mathrm{PF}_{6}$ quantitatively furnished DS2. Sequential addition and removal of $\mathrm{Cu}^{+}$(using cyclam followed by sonication at $50{ }^{\circ} \mathrm{C}$ for $30 \mathrm{~min}$ ) led to quantitative interconversion between the two assemblies DS1 and DS2 (Fig. 2a-e). The transformation DS1 $\rightarrow$ DS2 was confirmed by drastic upfield shifts of the ${ }^{1} \mathrm{H}-\mathrm{NMR}$ signals of protons $\mathrm{m}-\mathrm{H}$ and $\mathrm{l}-\mathrm{H}$ attributed to the shielding by the proximal second phenanthroline. These findings were further corroborated by ${ }^{1} \mathrm{H}$-DOSY NMR studies (ESI, $\dagger$ Fig. S24 and S25) which indicated a hydrodynamic radius change proportionate to the larger catenate slider-on-deck DS2 $\left(D=3.30 \times 10^{-10} \mathrm{~m}^{2} \mathrm{~s}^{-1}, r_{\mathrm{s}}=16.1 \AA\right)$ when compared to DS1 $\left(D=3.82 \times 10^{-10} \mathrm{~m}^{2} \mathrm{~s}^{-1}, r_{\mathrm{s}}=13.9 \AA\right)$.

To quantify the sliding exchange dynamics, we analyzed the ${ }^{1} \mathrm{H}$-NMR signals of DS1 at various temperatures. The diagnostic proton $\mathrm{r}-\mathrm{H}$ signal of the ZnPor units in DS1 was chosen because it appears as a sharp singlet (10.34 ppm) at $298 \mathrm{~K}$. VT ${ }^{1} \mathrm{H}-\mathrm{NMR}$ studies ${ }^{20}$ confirmed the dynamic coordination of both pyridine

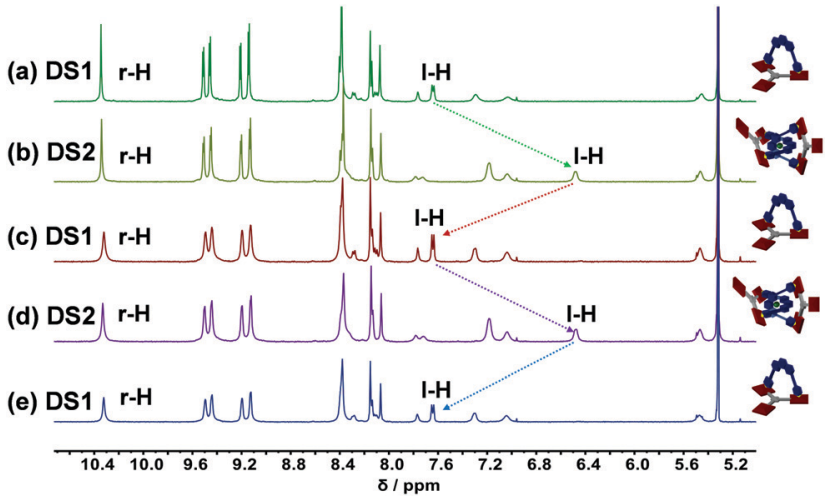

Fig. 2 Partial ${ }^{1} \mathrm{H}-\mathrm{NMR}\left(500 \mathrm{MHz}, \mathrm{CD}_{2} \mathrm{Cl}_{2}, 298 \mathrm{~K}\right)$ of the reversible interconversion between slider-on-deck DS1 to catenate slider-on-deck DS2 over 2.5 cycles. The quantitative catenation/decatenation was followed by monitoring the drastically different ${ }^{1} \mathrm{H}-\mathrm{NMR}$ signal of proton $\mathrm{L}-\mathrm{H}$. (a) Mixing ligands 1 and 2 in $1: 1$ ratio furnished DS1. (b) Addition of 0.5 equiv. of $\mathrm{Cu}^{+}$ furnished DS2 (catenation). (c) Addition of 0.5 equiv. of cyclam and sonication of the mixture at $50{ }^{\circ} \mathrm{C}$ for $30 \mathrm{~min}$ afforded DS1 (decatenation). (d) Addition of 0.5 equiv. of $\mathrm{Cu}^{+}$resulted in quantitative formation of DS2 (catenation). (e) Subsequent addition of cyclam followed by sonicating the mixture at $50{ }^{\circ} \mathrm{C}$ for 30 min furnished DS1 as a clean assembly (de-catenation).

terminals of the slider biped $\mathbf{1}$ to the three degenerate ZnPor stations of deck 2. Diagnostically, the sharp singlet at $298 \mathrm{~K}$ separated at $228 \mathrm{~K}$ into two singlets $(2: 1)$ at 10.32 and $10.40 \mathrm{ppm}$. While the rather sharp signal at $10.32 \mathrm{ppm}$ was assigned to both pyridine-coordinated zinc porphyrins, the freely rotating second zinc porphyrin furnished a broader signal at $10.40 \mathrm{ppm}$. A kinetic analysis provided the frequency $(k)$ for exchange at different temperatures (Fig. 3a) with $k=34.9 \mathrm{kHz} \mathrm{s}{ }^{-1}$ at $298 \mathrm{~K}$. The activation parameters are $\Delta H^{\ddagger}=52.2 \pm 0.7 \mathrm{~kJ} \mathrm{~mol}^{-1}$ and $\Delta S^{\ddagger}=$ $17.2 \pm 2.8 \mathrm{~J} \mathrm{~mol}^{-1} \mathrm{~K}^{-1}$ furnishing the free energy of activation for exchange at $298 \mathrm{~K}$ as $\Delta G_{298}^{\ddagger}=47.1 \pm 0.1 \mathrm{~kJ} \mathrm{~mol}^{-1}$ (ESI, $\dagger$ Fig. S28 and S29).

Analogously, the proton $\mathrm{r}-\mathrm{H}$ signal was chosen as the diagnostic parameter in the $\mathrm{VT}^{1} \mathrm{H}-\mathrm{NMR}$ for determining the dynamics of the catenate slider-on-deck DS2. At $298 \mathrm{~K}$, the r-H signal showed up as a sharp singlet (10.34 ppm). The VT ${ }^{1} \mathrm{H}-\mathrm{NMR}$ data thus confirmed the dynamic coordination of the tetratopic $\left[\mathrm{Cu}(\mathbf{1})_{2}\right] \mathrm{PF}_{6}$ with its four

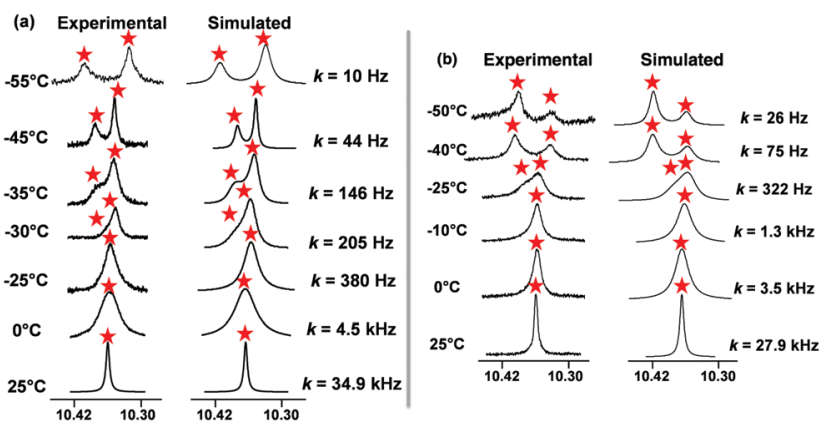

Fig. 3 The ${ }^{1} \mathrm{H}-\mathrm{VT}$-NMR $(600 \mathrm{MHz})$ was undertaken for both systems in $\mathrm{CD}_{2} \mathrm{Cl}_{2}$. Experimental and theoretical splitting of the proton signal of (a) $\mathrm{r}-\mathrm{H}$ in the slider-on-deck DS1, (b) $\mathrm{r}-\mathrm{H}$ in the catenate slider-on-deck DS2. 
pyridine terminals to the altogether $2 \times 3$ degenerate porphyrins from both identical decks 2 . At $233 \mathrm{~K}$, the sharp singlet of proton $\mathrm{r}-\mathrm{H}$ at $298 \mathrm{~K}$ separated into two singlets $(2: 1)$ at 10.40 and $10.32 \mathrm{ppm}$. Whereas the quite sharp signal at $10.40 \mathrm{ppm}$ was ascribed to the four pyridine-coordinated zinc porphyrins, the two freely rotating zinc porphyrin(s) displayed a broader signal at $10.32 \mathrm{ppm}$. A kinetic analysis provided the frequency ( $k$ ) for exchange at different temperatures (Fig. 3b) with $k_{298}=27.9 \mathrm{kHz}$ at $298 \mathrm{~K}$. The activation parameters are $\Delta H^{\ddagger}=48.9 \pm 0.7 \mathrm{~kJ} \mathrm{~mol}^{-1}$ and $\Delta S^{\ddagger}=3.2 \pm$ $2.6 \mathrm{~J} \mathrm{~mol}^{-1} \mathrm{~K}^{-1}$ furnishing the free energy of activation for exchange at $298 \mathrm{~K}$ as $\Delta G^{\ddagger}=47.9 \pm 0.1 \mathrm{~kJ} \mathrm{~mol}^{-1}$ (ESI, $\dagger$ Fig. S26 and S27).

For similar slider-on-deck systems ${ }^{21,22}$ we recently discussed various mechanistic options, but only one scenario agreed with the kinetic data. Alike, in both DS1 and DS2 the exchange could occur through complete dissociation followed by reassociation of $\mathbf{1}$ and $\mathbf{2}$ (intermolecular hopping) or a single $N_{\text {py }} \rightarrow$ ZnPor bond dissociation-rotation-association (sliding) mechanism. Since the barrier in a rotor ${ }^{23}$ operating via a welldefined single $N_{\text {py }} \rightarrow$ ZnPor dissociation amounted to $\Delta G^{\ddagger}=$ $47.6 \pm 0.1 \mathrm{~kJ} \mathrm{~mol}^{-1}$, the pathway involving complete dissociation is rigorously ruled out for DS1 and DS2 as their barriers are almost identical to that of the rotor: $\Delta G^{\ddagger}($ DS1 $)=47.1 \pm$ $0.1 \mathrm{~kJ} \mathrm{~mol}^{-1}$ and $\Delta G^{\ddagger}($ DS2 $)=47.9 \pm 0.1 \mathrm{~kJ} \mathrm{~mol}^{-1}$.

Comparing the kinetic data of both slider-on-deck systems leads us to interesting mechanistic corollaries. Specifically, one could hypothesize that the exchange motion at both ZnPor decks of DS2 could be either coupled or decoupled. If the exchange would be decoupled, i.e. the motion at both decks is fully independent, then the frequency should be identical to that of DS1. If it were coupled, positions at deck A and B would communicate and then a full exchange would require that all combinations be passed through equally. As a result, the frequency could be derived from the exchange rate at the single site in DS1 and a statistical correction. In principle, this constitutes a case of multiplicative constrained probabilities as $P_{(\text {total })}=P_{(\text {event } 1)} \times P_{(\text {event } 2 \text {; given event } 1 \text { has happened })}$. In the coupled case one would expect $P_{(\text {total })}=(1 / 3) \times(1)=1 / 3$. However, the observed rate of DS2 is not $1 / 3$ that of DS1; the frequency at DS2 is only slower by $10-15 \%$. On the other hand, the two rates are not identical, as expected for the decoupled case. Rather they remain different even considering the error range $\left(k_{298}=34.9 \pm 1.8 \mathrm{kHz}\right.$ for DS1 and $k_{298}=27.9 \pm 1.4 \mathrm{kHz}$ for DS2). Nevertheless, it is obvious to postulate for DS2 that the motion at both decks is decoupled. But why is the observed frequency lower? We can exclude metal coordination at the remote phenanthroline to be responsible for this effect. Actually, metal coordination should lower the donor quality of the pyridine feet in the $N_{\text {py }} \rightarrow$ ZnPor interaction. As a net effect, in such case, exchange in DS2 should be faster than in DS1, contrary to our findings.

Ultimately, an inspection of the DFT-computed slider-ondeck structures provides a convincing reason for the rate differences. The data suggest that biped 1 in DS1 (ESI, $\dagger$ Fig. S35) is strained once axial $N_{\text {py }} \rightarrow$ ZnPor coordination at both ZnPor units is realized. The strain is indirectly visible from the intramolecular pyridine-pyridine distance when one compares the

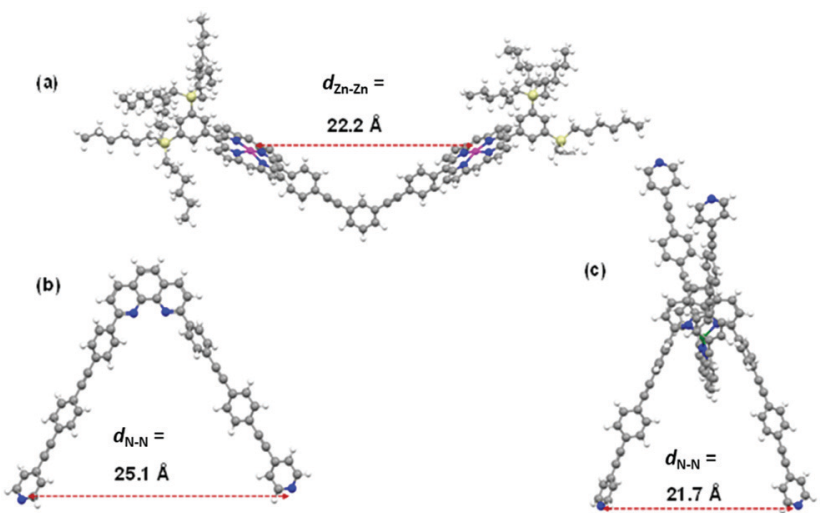

Fig. 4 Ball and stick representation of (a) partial structure of deck 2. (b) Structure of biped 1. (c) Structure of $\left[\mathrm{Cu}(\mathbf{1})_{2}\right]^{+}$. All figures show the energy-minimized structures (B3LYP/6-31G(d); Lanl2dz basis set for metals). Counter anions are not included.

$d\left(N_{\mathrm{py}}-N_{\mathrm{py}}{ }^{\prime}\right)$ of the free biped $\mathbf{1}$ in its unstrained state with the one enforced for 1 when combining with deck 2 in DS1, i.e. 25.1 vs. 22.2 A, respectively (Fig. 4a and b). Consequently, some release of strain energy is expected to promote the $N_{\text {py }} \rightarrow$ ZnPor dissociation step in DS1. On the other hand, the computed $\left[\mathrm{Cu}(\mathbf{1})_{2}\right]^{+}$fragment in DS2 (ESI, $\uparrow$ Fig. S36) has an intramolecular pyridine-pyridine distance $d\left(N_{\text {py }}-N_{\text {py }}^{\prime}\right)=21.7 \AA$ that almost exactly matches that of the unstrained free deck $2\{d(\mathrm{Zn}-\mathrm{Zn})=22.2 \AA$ A $\}$ (Fig. 4a and c) leading to a possibly strain-free axial $N_{\text {py }} \rightarrow$ ZnPor coordination in DS2. The reduced $N_{\text {py }}-N_{\text {py }}^{\prime}$ distance in the $\left[\mathrm{Cu}(\mathbf{1})_{2}\right]^{+}$unit as compared to that in 1 indicates a long-range effect of the $\mathrm{Cu}^{+}$coordination on the biped's spatial arrangement. This finding points to an allosteric effect originating from the four-fold $\pi-\pi$ stacking between the 2,9-phenyl groups with the opposite phenanthroline's $\pi$ cloud in the homoleptic complex $\left[\mathrm{Cu}(\mathbf{1})_{2}\right] \mathrm{PF}_{6}$.

Finally, due to the reduced strain release in the transition state of the exchange in DS2 as compared to that in DS1, the slower sliding speed of $27.9 \pm 1.4 \mathrm{kHz}$ in DS2 is readily understood ( $c f$. DS1, $k=34.9 \pm 1.8 \mathrm{kHz}$ ).

In summary, we have demonstrated two dynamic slider-ondeck systems that are quantitatively and reversibly toggled through catenation/decatenation. The interconversion between the two-component macrocyclic and the three-component slider-on-deck catenate is accomplished by addition and removal of $\mathrm{Cu}^{+}$ions. A rigorous kinetic analysis of the threevs. nine-fold degenerate rearrangement indicates that allosteric effects are switched off/on in the DS1 $\leftrightarrows$ DS2 transformation. The fine tuning of dynamic allosteric effects in switchable multicomponent assemblies opens new routes for the modulation of molecular machine processes.

We are indebted to the University of Siegen, Dr Thomas Paululat (Siegen) and the Deutsche Forschungsgemeinschaft (Schm 647/20-2) for continued support.

\section{Conflicts of interest}

There are no conflicts to declare. 


\section{Notes and references}

1 S.-L. Huang, T. S. A. Hor and G.-X. Jin, Coord. Chem. Rev., 2017, 333, 1-26.

2 S. Erbas-Cakmak, D. A. Leigh, C. T. McTernan and A. L. Nussbaumer, Chem. Rev., 2015, 115, 10081-10206.

3 J.-P. Sauvage, Angew. Chem., Int. Ed., 2017, 56, 11080-11093.

4 J. F. Stoddart, Angew. Chem., Int. Ed., 2017, 56, 11094-11125.

5 M. R. Wilson, J. Solà, A. Carlone, S. M. Goldup, N. Lebrasseur and D. A. Leigh, Nature, 2016, 534, 235-240.

6 S. Grunder, P. L. McGrier, A. C. Whalley, M. M. Boyle, C. Stern and J. F. Stoddart, J. Am. Chem. Soc., 2013, 135, 17691-17694.

7 C. P. Collier, G. Mattersteig, E. W. Wong, Y. Luo, K. Beverly, J. Sampaio, F. M. Raymo, J. F. Stoddart and J. R. Heath, Science, 2000, 289, 1172-1175.

8 (a) Y. Liu, A. Kuzuya, R. Sha, J. Guillaume, R. Wang, J. W. Canary and N. C. Seeman, J. Am. Chem. Soc., 2008, 130, 10882-10883; (b) J. Elbaz, Z.-G. Wang, F. Wang and I. Willner, Angew. Chem., Int. Ed., 2012, 51, 2349-2353.

9 M. Cesario, C. O. Dietrich-Buchecker, J. Guilhem, C. Pascard and J. P. Sauvage, J. Chem. Soc., Chem. Commun., 1985, 244-247.

10 B. Korybut-Daszkiewicz, A. Więckowska, R. Bilewicz, S. Domagała and K. Woźniak, Angew. Chem., Int. Ed., 2004, 43, 1668-1672.

11 P. Mobian, J.-M. Kern and J.-P. Sauvage, Angew. Chem., Int. Ed., 2004, 43, 2392-2395.

12 N. H. Evans, C. J. Serpell and P. D. Beer, Chem. - Eur. J., 2011, 17, 7734-7738.

13 A. Goswami and M. Schmittel, Coord. Chem. Rev., 2018, 376, 478-505.
14 (a) M. Fujita and K. Ogura, Coord. Chem. Rev., 1996, 148, 249-264; (b) C. Dietrich-Buchecker, B. Colasson, M. Fujita, A. Hori, N. Geum, S. Sakamoto, K. Yamaguchi and J.-P. Sauvage, J. Am. Chem. Soc., 2003, 125, 5717-5725; (c) S. Prusty, S. Krishnaswamy, S. Bandi, B. Chandrika, J. Luo, J. S. McIndoe, G. S. Hanan and D. K. Chand, Chem. - Eur. J., 2015, 21, 15174-15187; (d) T. Sawada, M. Yamagami, K. Ohara, K. Yamaguchi and M. Fujita, Angew. Chem., Int. Ed., 2016, 55, 4519-4522.

15 N. H. Evans and P. D. Beer, Chem. Soc. Rev., 2014, 43, 4658-4683.

16 J. Valero, N. Pal, S. Dhakal, N. G. Walter and M. Famulok, Nat. Nanotechnol., 2018, 13, 496-503.

17 A. Goswami, S. Saha, P. K. Biswas and M. Schmittel, Chem. Rev., 2020, 120, 125-199.

18 M. Beyler, V. Heitz and J.-P. Sauvage, J. Am. Chem. Soc., 2010, 132, 4409-4417.

19 (a) N. Mittal, M. L. Saha and M. Schmittel, Chem. Commun., 2015, 51, 15514-15517; (b) S. De, S. Pramanik and M. Schmittel, Angew. Chem., Int. Ed., 2014, 53, 14255-14259.

20 (a) A. Goswami and M. Schmittel, Angew. Chem., Int. Ed., 2020, 59, 12362-12366; (b) S. Saha, P. K. Biswas, I. Paul and M. Schmittel, Chem. Commun., 2019, 55, 14733-14736; (c) A. Goswami, S. Pramanik and M. Schmittel, Chem. Commun., 2018, 54, 3955-3958.

21 I. Paul, A. Goswami, N. Mittal and M. Schmittel, Angew. Chem., Int. Ed., 2018, 57, 354-358.

22 A. Ghosh, I. Paul, S. Saha, T. Paululat and M. Schmittel, Org. Lett., 2018, 20, 7973-7976.

23 A. Goswami, I. Paul and M. Schmittel, Chem. Commun., 2017, 53, 5186-5189. 